\title{
Funded pensions, labor market participation, and economic growth ${ }^{1}$
}

\author{
Mark A. Roberts \\ University of Nottingham \\ Eric O’N. Fisher \\ The Ohio State University
}

Keywords: social welfare state, labor force participation, economic growth

\begin{abstract}
.
This paper analyses a model of overlapping generations in which agents who do not participate in the labor market are unable to borrow. Thus an increase in a fully funded pension raises aggregate savings even with a fixed participation rate since private savings are not crowded out one-for-one. When labor force participation is determined endogenously, a rise in the level of fully funded pensions increases the aggregate labor supply. This in turn increases aggregate savings and growth, directly by raising per capita savings and indirectly through tax and interest rate effects.
\end{abstract}

\section{Introduction}

\footnotetext{
This paper is part of the research project, "Social security initiatives and economic growth", which is financed by the ESRC under the Evolving Macroeconomy Programme. The authors would like to thank the Economic Policy Research Unit at the University of Copenhagen for the hospitality that made part of this research possible. They also thank seminar participants at the 2000 Manchester Conference on Growth and Business Cycles and at The Ohio State University for comments on earlier drafts.
} 
The reform of state pensions, namely the abandonment of the traditional unfunded plans, is very much on the agenda. One question is whether the alternative should be a fully funded public scheme or one where individuals are encouraged to make private savings and borrowing decisions. These two possibilities are imperfect substitutes if some agents are unable to obtain loan finance. We consider the implications of household borrowing constraints in an endogenous growth model and show moving to a fully funded state pension may enhance growth.

The general effects of borrowing constraints on growth are ambiguous. Jappelli and Pagano (1994) present a model where household borrowing constraints enhance growth because they decrease consumption and thus free loanable funds for investment. DeGregorio (1996) shows that the same constraints may reduce growth by restricting investment in human capital. Its sign will depend in general on the extent to which individuals borrow in order to finance consumption instead of investment in human capital. We consider the former, where borrowing constraints are beneficial for growth.

In modern economies, however, the empirical relevance of financing constraints on the growth process may actually be small. Jappelli (1990) reports the consensus that only twenty percent of the households in the United States are credit constrained. We show that even if only a small share of households are constrained in financial markets, there may be a significant effect on the growth process. Although only a small share of households bear the full brunt of credit constraints, their inframarginal effects are significant for the entire economy.

The paper models aspects of the financial market and the labor market in an extended version of the Diamond (1965) overlapping generations model. Although the labor-leisure tradeoff and labor union effects are sometimes analyzed within this 
framework, it is less common to model labor force participation. ${ }^{2}$ An important aspect of our model is that, while the demand for funds derives as usual from the corporate sector's investment decisions, their supply is derived from only households who are employed.

This fact hinges on the key assumption that households that do not participate in the labor market are unable to borrow. There is both a sociological and an economic rationale for the assumption of discriminatory borrowing constraints. First, not participating in the labor market may lead to social exclusion and a loss of status, perhaps a form of financial collateral. Second, consumption smoothing implies that the lower relative incomes of non-participants early in the life cycle will give them a tendency to borrow.

Household borrowing constraints affect the individual's participation decision. This choice is based on a comparison of the utility of participating--including an idiosyncratic dis-utility of effort--with that of opting out of the labor force. A person outside the labor force incurs both a lower income early in the life cycle and an inability to borrow against future social welfare payments. Thus the inability to borrow has repercussions for the aggregate supply of labor.

The central concern of our paper, however, is the effect of a fully funded social security plan on economic activity and growth. Of course, if financial markets were complete, a fully funded retirement program would have no effect on capital accumulation and growth. But in a model with borrowing constraints, an increase in fully funded old-age benefits does influence economic growth. An increase in such benefits raises total savings. Since people out of the labor force cannot offset

${ }^{2}$ Individual labor supply is considered in Homburg (1990), Breyer and Straub (1993) and Raffelhueschen (1993), and labor union effects are discussed in Demmel and Keuschnigg (2000). The 
increased old-age benefits by borrowing, crowding out is less than complete. Indeed, the increase in aggregate savings is related in a very simple way to the proportion of non-participants in the household sector. Further, an increase in old-age benefits will actually raise aggregate labor supply. Fully funded social security is effectively a form of forced savings that cannot be offset by individuals who are constrained from borrowing. Thus increased old-age benefits raise the cost of not participating in the labor market.

Increasing labor force participation will in turn raise aggregate savings. Since those out of work face a finance constraint, a rise in the labor supply is tantamount to a rise in the number of savers. Also, savings per participant may increase. Indeed, there are two positive mechanisms and a negative one. A rise in participation or employment raises the marginal product of capital and thus the rate of interest. This will increase savings. Also, greater labor force participation lowers taxes since they are used in part to fund unemployment benefits. This second effect raises savings since it increases disposable incomes. The third effect is that the increased supply of labor drives down the current real wage. Nevertheless, aggregate savings must rise, since the adverse wage effect is dominated by the employment effect because firms' demand for labor is elastic.

The rest of the paper is organized as follows. The model and its equilibrium are given in Section 2, while Section 3 describes some properties of a balanced growth path. Section 4 gives a brief history of the advent of the social welfare state in Europe at the end of the nineteenth century, and Section 5 calibrates the model to German data from that period. Section 6 offers a brief summary.

common focus of these papers is on how pensions reform may alleviate the labor market distortions 


\section{The model and its equilibrium}

There is a measure of $M_{t}$ agents in generation $t \geq 0$, with exogenous population growth at the rate $n$ per generation. The utility of a type-j agent born in period $t \geq 1$ is given by this function:

$$
U\left(c_{t}^{j}, c_{t+1}^{j}, \phi_{t}^{j}\right)=\left(c_{t}^{j} \frac{\sigma-1}{\sigma}+\frac{1}{1+\theta} c_{t+1}^{j} \frac{\sigma-1}{\sigma}\right)^{\frac{\sigma}{\sigma-1}}-\phi_{t}^{j}
$$

where $c_{t}^{j}$ is consumption at time $\mathrm{t}$ by a type- $\mathrm{j}$ agent and $\phi_{t}^{j} \geq 0$ is that agent's (perhaps time-dependent) fixed cost of working. ${ }^{3}$ The index $j \in\left[0, M_{t}\right]$ and agents are uniformly distributed on this support, and we assume that $\phi_{t}^{j}$ is increasing in $\mathrm{j}$; thus agents are ranked according to their idiosyncratic (perhaps time-dependent) dis-utility of effort. The decision to participate in the labor market involves a fundamental nonconvexity: either the agent is in the labor force and incurs the fixed utility loss $\phi_{t}^{j}$ or he is not and incurs no such loss. ${ }^{4}$ The parameter $\sigma>0$ is the inter-temporal elasticity of substitution, and the parameter $\theta>0$ is the subjective discount factor measured at the length of a working life.

If an agent $j \in\left[0, M_{t}\right]$ is not constrained in his savings decision, then the utility function (1) gives rise to the corresponding savings function:

\footnotetext{
caused by pay-as-you-go systems.

${ }^{3}$ The utility of an agent born in generation 0 is just $U\left(c_{1}\right)=c_{1}$.

${ }^{4}$ This assumption is akin to the Rogerson's (1988) notion that a job is lumpy. Either one works a whole job or one does not work at all.
} 


$$
s\left(y_{t}^{j}, y_{t+1}^{j}, 1+r_{t+1}\right)=\left(1+(1+\theta)^{\sigma}\left(1+r_{t+1}\right)^{1-\sigma}\right)^{-1}\left(y_{t}^{j}-\left(\frac{1+\theta}{1+r_{t+1}}\right)^{\sigma} y_{t+1}^{j}\right)
$$

where $y_{t}^{j}$ is income at time $\mathrm{t}$ and $r_{t+1}$ is the real rate of return on savings held from period $t$ through period $t+1$. Since the dis-utility of effort is separable, this savings function does not depend upon an agent's type within a generation.

Let the indirect utility of a type $\mathrm{j}$ agent who is in the labor force be $V\left(y_{t}^{j}, y_{t+1}^{j}, 1+r_{t+1}, \phi_{t}^{j}\right)$. This is the maximal value of (1) subject to $c_{t}^{j}+\left(1+r_{t+1}\right)^{-1} c_{t+1}^{j} \leq y_{t}^{j}+\left(1+r_{t+1}\right)^{-1} y_{t+1}^{j}$. The indirect utility of an agent who is constrained in his savings decision is just $\tilde{V}\left(y_{t}^{j}, y_{t+1}^{j}\right)=U\left(y_{t}^{j}, y_{t+i}^{j}\right)$, where we have imposed implicitly that the agent gives up no leisure, as he is not in the labor force. An agent who is in the labor force earns the going wage $w_{t}$ and pays income and payroll taxes in the amount $\tau_{t}$. The government earmarks $b_{t}$ of these taxes for his pension. An agent who does not participate in the labor force receives a net benefit of $d_{t}-\tau_{t}$ in the first period, and $b_{t}$ of his taxes is also put into a fully funded pension scheme. All agents retire in the second period of their lives and receive a pension benefit of $\left(1+r_{t+1}\right) b_{t}$. Thus an agent $j \in\left[0, M_{t}\right]$ participates in the labor force if and only if

$$
V\left(w_{t}-\tau_{t},\left(1+r_{t+1}\right) b_{t}, 1+r_{t+1}, \phi_{t}^{j}\right) \geq \tilde{V}\left(d_{t}-\tau_{t},\left(1+r_{t+1}\right) b_{t}\right)
$$


Thus there will be a critical value $0 \leq \widetilde{j}_{t} \leq M_{t}$ such that all types $j \leq \widetilde{j}_{t}$ are in the labor force and all types $j>\widetilde{j}_{t}$ are not. Since the types are uniformly distributed, the fraction of the population that is in the labor force is $\tilde{j}_{t} / M_{t}$.

The government runs a balanced budget in each generation. Thus its policy satisfies

$$
\tau_{t}=b_{t}+\left(1-\tilde{j}_{t} / M_{t}\right) d_{t}
$$

Note that $d_{t} \geq \tau_{t}+b_{t}$ is necessary for agents receiving public benefits to cover their income and social insurance taxes. Also, a simple manipulation of (2) shows that agents outside the labor force are constrained in their borrowing decisions only if $\left(d_{t}-\tau_{t}\right) / b_{t}<\left(1+r_{t+1}\right)^{1-\sigma}(1+\theta)^{\sigma}$, which is true if real interest rates are positive and public subsidies to those outside the labor force are not too generous. It is possible to show that a higher labor force participation rate entails a lower tax rate since fewer people are on the dole. This fact implies that a representative individual will be less inclined to borrow because disposable income is higher earlier in the life cycle.

The private and social returns to capital differ because there is an economywide externality as in Romer (1988). Let firms be indexed by $i \in[0,1]$; then the output of the $i-t h$ firm is:

$$
Y_{t}(i)=\left[A K_{t}^{1-\alpha} M_{t}^{-\beta}\right]\left[K_{t}(i)\right]^{\alpha}\left[L_{t}(i)\right]^{\beta} .
$$


where $Y_{t}(i)$ is the firm's output, $K_{t}=\int K_{t}(i) d i$ is the aggregate capital stock, $K_{t}(i)$ is firm's input of capital and $L_{t}(i)$ its input of labor. We impose $\alpha>0, \beta>0$, and $\alpha+\beta=1$, thus assuming constant returns to scale at the firm level. The first term in brackets captures the economy-wide growth externality, and the second and third terms are the firms' own private inputs. Notice that the growth externality depends upon the size of the potential labor force. Also, the parameters have been chosen so that aggregate output is linear in the aggregate stock of capital in an economy with a continuum of identical firms. If all the firms employ the same number of workers and use the same amount of capital as input, then (5) implies that per capita output is:

$$
y_{t}=\int\left[Y_{t}(i) / L_{t}(i)\right] d i=A k_{t}\left[\tilde{j}_{t} / M_{t}\right]^{\beta}
$$

where $k_{t}=K_{t} / M_{t}$ is the per capita capital stock. If the labor force participation rate is constant, then output per person rises at the rate of growth of the capital stock per worker.

The members of generation 0 are endowed with the economy's initial capital stock, and members of any other generation are endowed with one unit of labor when young and nothing when old. Thus agents in the workforce save in order to smooth consumption during the course of the life times. This is the source of funds for private investment; the government uses its social insurance revenues to purchase capital as well. Let $\Pi=\left(d_{t}, b_{t}, \tau_{t}\right)_{t=1}^{\infty}$ be a sequence satisfying (4) and let the initial capital stock $k_{1}$ be given. Then equilibrium in the economy is a list of factor prices $\left(w_{t}, r_{t+1}\right)_{t=1}^{\infty}$, a labor force participation rule $\left(\tilde{j}_{t}\right)_{t=1}^{\infty}$, and corresponding aggregate 
quantities $\left(y_{t}, k_{t+1}\right)_{t=1}^{\infty}$ such that: (i) agents $j \in\left[0, \tilde{j}_{t}\right]$ maximize utility subject to the usual inter-temporal budget constraint; (ii) firms maximize profits taking the aggregate capital stock as given; (iii) agents $j \in\left[\tilde{j}_{t}, M_{t}\right]$ are constrained in their borrowing decisions; and (iv) goods markets and factor markets clear in each period.

There are two immediate implications of this definition. First, each firm has the same capital-labor ratio. Second, the sum of private and public savings determines investment and thus next period's capital stock per person:

$$
k_{t+1}=(1+n)^{-1}\left[\left(\tilde{j}_{t} / M_{t}\right) s\left(w_{t}-\tau_{t},\left(1+r_{t+1}\right) b_{t}, 1+r_{t+1}\right)+b_{t}\right] .
$$

Equation (6) is perhaps the single best description of equilibrium. It shows that there is a balanced growth path if the labor force participation rate is constant and if taxes and benefits are all indexed to the wage rate.

\section{Properties of the equilibrium}

Profit maximization implies that the real wage is $w_{t}=\beta A\left(\tilde{j}_{t} / M_{t}\right)^{\beta-1} k_{t}$ and the real interest rate is $r_{t}=\alpha A\left(\tilde{j}_{t} / M_{t}\right)^{\beta}$. Thus the real wage is decreasing in the labor force participation rate, and the real interest rate is increasing in it. Also, if the labor force participation rate is constant, then the real interest rate is constant, and the real wage, the capital stock and gross domestic product all grow at the same rate.

Write the sum of public and private savings as $S_{t}=\left(\tilde{j}_{t} / m_{t}\right) s\left(w_{t}-\tau_{t},\left(1+r_{t+1}\right) b_{t}, 1+r_{t+1}\right)+b_{t}$. Using the government budget balance (4), we can derive another important aspect of the equilibrium: 


$$
\partial S_{t} / \partial b_{t}=\left(M_{t}-\tilde{j}_{t}\right) / M_{t}
$$

Thus increasing the pension benefit without changing any other aspect of government policy will raise aggregate savings by the unemployment rate. Since the pension benefit is fully funded and pays the market rate of return, marginal changes in its level have no effect on the savings of unconstrained households. But such a change raises economy-wide savings precisely in proportion to the number of households who do not participate in the credit market.

The labor supply decision is the central aspect of the model. We assume that the dis-utility from working is uniformly distributed across the population with support $\left[0, \Phi_{t}\right]$. Thus people in each generation are ranked from those who incur no psychic fixed cost upon entering the labor force to those who incur the maximal fixed cost $\Phi_{t}$. The maximal element of this support depends upon time because agents' attitudes towards work may have sociological components inherent in them. We are fully cognizant of the fact that we are breaking an economist's taboo in mixing technological parameters with agents' preferences, but we think that this specification is warranted by historical experience. Indeed, in the simulations described below, we index $\Phi_{t}$ to $w_{t}=\beta A k_{t}$, the wage that occurs if there is maximal participation in the labor force.

Since the real interest rate depends upon future labor force participation, there is a forward-looking dynamic in the model. Equation (2) shows that current savings and thus investment depend upon next period's interest rate. Thus the participation rate-and by extension all other endogenous variables--cannot be solved independent of the behavior of the economy on its transition to a balanced growth path. Still, it is easy to 
see that if $\Phi_{t} \leq A \beta k_{t}$ then all agents will participate in the labor market. Thus in a growing economy, any specification of the dis-utility of having a job that does not rise at the rate of growth of the economy will entail complete labor force participation asymptotically.

Assume that public policy is such that $d_{t}=d w_{t}$ and $b_{t}=b w_{t}$, and assume further that the upper bound for the distribution of the fixed costs of working is $\Phi_{t}=\Phi w_{t}$. Then there is a balanced growth path for this economy. Finally, it is convenient to write $u_{t}=\left(M_{t}-\tilde{j}_{t}\right) / M_{t}$ as the share of people out of the work force; its value on a balanced path is just $u$, and the concomitant participation rate is $1-u$. Using (2) and (6), we see that on such a path the per capita growth rate is:

$$
1+g=(1+n)^{-1} \beta A(1-u)^{\beta-1}\left(\frac{(1-u)(1-u d)}{1+(1+\theta)^{\sigma}\left(1+\alpha A(1-u)^{\beta}\right)^{1-\sigma}}+b u\right) .
$$

Several comments about (8) are warranted. First, the growth rate increases with the size of the economy, an artifact of the assumption that the marginal private and social products of capital differ. Second, the growth rate depends positively upon labor's share of output, since wages are the source of savings. Third, the growth rate depends positively upon labor force participation rate. Thus increasing the fixed psychic cost of having a job will lower the growth rate. Fourth the per capita growth rate is negatively related to population growth and to the discounting parameter. And finally, the growth rate depends positively upon the pension benefit, since that is the only way that people outside the labor market can save. ${ }^{5}$

\footnotetext{
${ }^{5}$ Although an increase in fully funded pensions may raise the growth rate, this will not be Paretoimproving. For example, individuals who still choose not to participate will be made worse-off.
} 


\section{Brief Elements of Social Welfare Policies in Several European Countries}

There is a remarkable coincidence between the increase of the growth rates of the major industrial countries in the 1870's and beginnings of the Welfare State. Maddison (1982) identifies three major phases of capitalist development and emphasizes that the growth rate of the industrial economies actually accelerated during each shift of regime. ${ }^{6}$ The nineteenth century also witnessed the beginnings of the roots of the social welfare state; many authors cite the direct connection between the British Poor Laws and Bismarck's first policies concerning social insurance. ${ }^{7}$ A simplistic explanation for the rise of the welfare state is that the political economy of redistribution is a luxury that an increasing affluent body politic "purchases" at the ballot box.

The Bismarckian policies were instituted of course not as fully funded but as pay-as-you-go plans. One might think that the concomitant crowding out would reduce the long-term growth rate, but the model suggests that increased pension benefits might actually mitigate this effect to some extent, especially if the increased benefits offset the potentially deleterious effects of social insurance on long-run laborforce participation.

The model has only two policy variables that summarize a more complicated array of actual social welfare programs. Hansen (1997) identifies six salient aspects of these programs: illness insurance, unemployment insurance, payments for injuries sustained at work, retirement insurance, family allowance, and maternity leave. In our stylized model, all but one of these is captured by the policy parameter $d_{t}$. Thus,

\footnotetext{
${ }^{6}$ During the period from 1750 until 1785 , Holland was the productivity leader and world growth was essentially stagnant. From 1785 to 1890 , the United Kingdom was the productivity leader, and the leading country grew at about $1.0 \%$ per man-hour per annum. After 1890, the United States became the leader and the analogous rate accelerated to $2.3 \%$.

${ }^{7}$ See Mommsen and Mock's (1981) The Emergence of the Welfare State in Britain and Germany.
} 
while we speak loosely of "unemployment benefits," this parameter captures any aspect of the social welfare system that tends to lower labor-force participation permanently. Indeed, no unemployment insurance scheme in Denmark, Sweden, Finland, Germany, the Netherlands, or Great Britain has provisions for permanent payments. Some countries do have unemployment benefits that last as long as seven years, and the replacement rates for these benefits are quite high, much more generous than the parameter we use in the simulation below. Still, it is perhaps best to interpret the policy parameter $d_{t}$ as an amalgam of income maintenance payments and other social welfare benefits that tend to decrease the long-run rate of participation in the labor force.

The policy parameter $b_{t}$ captures retirement insurance or a public pension. In all of all of the above countries but Germany, every person is entitled to a public pension regardless of work history. And these pension benefits can be quite generous: the maximal pensions entail replacement rates that cluster around $55 \%$ of the income of the average working person. In the simulation below, we chose a fairly conservative public pension benefit of $20 \%$ of the average working person's income. Again, in the calibration below, it is best to think of these public pension benefits as a combination of income maintenance and other benefits for people who have a very checkered work history.

\section{Calibrating the model}

We fitted the model to data for the economy of Germany from Maddison (1982). It is worth emphasizing that we are calibrating our model to data from an economy that instituted a pay-as-you-go scheme of social welfare benefits. It is likely that these programs crowd out capital accumulation and thus slow long-run growth. Hence the calibrations in this section underestimate the growth rates that would have occurred if 
the Bismarckian reforms had been fully funded. In a model with increasing returns to capital in the aggregate, this fact implies that we are perhaps being conservative about the long-run effects of changing pension benefits.

The base case simulates a social welfare state with both moderate unemployment and pension benefits. We set $d=.4$ and $b=.2$; the corresponding tax rate was 21.2\%. Thus this configuration of policy parameters implies that the net (permanent) social benefits accruing to a person of working age outside the labor force were about $19 \%$ of the full employment wage. The base year was 1870 , and we considered each generation to be a period of 25 years.

The rate of population growth was set at $10.3 \%$ per generation, matching the increase from 39.2 millions to 61.4 millions between 1870 and 1979. Maddison reports that $61.4 \%$ of the total population was between 15 and 64 years old in 1870 . We assumed that the female labor force participation rate was zero in 1870 , and thus calibrated the initial size of the labor force at 12,043,00 workers.

We assumed that the subjective discount rate was $\theta=1.7$, implying an annual discount rate of $4 \%$, and we set the inter-temporal elasticity of substitution at $\sigma=2$, in keeping with the middle value suggested by Lucas (1988). Capital's share in output was set at $\alpha=.33$, and labor's share was thus $\beta=.67$. These numbers reflect the fact that measured factor shares in the industrial economies has been fairly constant over a long horizon, and many other studies use these shares.

It is of course important to describe the distribution of the idiosyncratic dis-utility of work. We assumed that the $\phi_{t}^{j}$ 's were uniformly distributed on the interval $\left[0,0.935 \beta A k_{t}\right]$. This support was chosen with the intent of replicating a long-term unemployment rate of 3\%, a figure that is perhaps a bit low for the German economy. 
Still, unemployment is very cyclical, and we wanted to have a conservative base case. Thus the calibrated labor force participation rate was $97 \%$.

The two most difficult numbers to calibrate in this class of growth models are the initial capital stock and the value of $A$, the constant relating the output with the corresponding capital stock. Maddison estimates that the stock of gross nonresidential fixed capital in Germany in 1976 was 808 billions of 1970 dollars. Using his index numbers, ${ }^{8}$ we find that the analogous stock of capital in 1870 was 31.2 billion 1970 dollars. Maddison also estimates that the German gross domestic product per capita in 1870 was 5351970 dollars. ${ }^{9}$ In our model, this fact implies that $A=.66$, but that number is much too small for the calibrated economy because the real interested rate is too low. Maddison calculates that the German economy grew about $2.47 \%$ per annum per capita between 1870 and 1979 . Setting $A=11.5$, we see that the model fits the long-run growth rate inherent in the data well. In particular, the annual growth rate is $2.45 \%$ and the real interest rate is $5.4 \% .^{10}$

Finally, we can get a sense of the importance of pension benefits in the secondbest economy with taxes by raising benefits from $b=.2$ to $b=.21$, while keeping the dole rate unchanged. This policy happens to be tax-neutral, so the net unemployment benefits are unchanged. The one-percent rise in the pension rate increases labor force participation from $97 \%$ to $99.5 \%$. Also, there is a rise in the long-run growth rate, from $2.45 \%$ to $2.56 \%$ per annum. As Lucas (1988) has emphasized, seemingly small

\footnotetext{
${ }^{8}$ The index for Germany is calculated for net non-residential fixed capital, and we are thus assuming that the depreciation rate is constant.

${ }^{9}$ Indeed, the ratio between the measured stock of capital and gross domestic product per capita has been remarkably constant, and Maddison's estimates for this ration in the Germans economy is about 2.9 .

${ }^{10}$ Unfortunately, the value $A=11.5$ significantly overstates the level of GDP in 1870 . And to complicate matters further, the value $A=130$ arises from the usual Solow growth account in the base year 1870. This leads us to believe that the economy-wide growth externality that is inherent in this class of models makes their calibration very sensitive to the possibility that the base-year aggregate capital stock is mis-measured.
} 
changes in the growth rate can have enormous effects in the long run. It is worth emphasizing again that this increase in growth is affected through two channels. First, the higher pension benefits induce an increase in worker participation rates because the effect of being constrained in the credit market is now more onerous. And second, higher pension benefits increase economy-wide savings.

\section{Conclusion}

We have analyzed an important aspect replacing a pay-as-you-go social security plan with a fully funded one. Should policy makers resort to a funded public scheme or to a private one? Our model has shown that a fully funded scheme may raise the rates both of labor participation and of growth. Countries with more generous schemes are predicted to have lower unemployment rates and faster growth.

The calibration suggests that there can be a significant empirical effect of increasing a fully funded social security system, even when the level of nonparticipation is fairly small. A modest rise in pension benefits increases the labor force participation rate in a plausibly calibrated economy by more than two percent. It also increases the long-run growth rate by about one-tenth of a percent.

The analysis in this paper occurs in a second-best world where some agents are unable to borrow. It should be stressed that the actual incidence of credit constraints need not be high for the model's results to hold; it is only necessary that their discriminatory nature affects incentives at the margin. Consequently, the model is able to capture the characteristics of a developed economy in which there is a role for public policy. 


\section{References}

Breyer, F. and Straub, M. "Welfare Effects of Unfunded Pensions Systems when labor supply is endogenous." Journal of Public Economics, 50 (1993), 77-91.

DeGregorio, J. "Borrowing Constraints, Human Capital Accumulation and Growth." Journal of Monetary Economics, 37 (1996), 49-71.

Demmel, R. and Keuschnigg, C. "Funded Pensions and Unemployment", Finanzarchiv 57 (2000), 22-38.

Diamond, P. A. "National Debt in a Neoclassical Growth Model." American Economic Review 55 (1965), 1126-50.

Hansen, H. Elements of Social Security in Six European Countries. Danish Institute of Social Research: Copenhagen, 1997.

Homburg, S. "The Efficiency of Unfunded Pension Schemes", Journal of Institutional and Theoretical Economics 146 (1990), 640-647.

Jappelli, T. "Who is Credit Constrained in the US Economy?" Quarterly Journal of Economics, 105 (1990), 219-234.

Jappelli, T. and Pagano, M. "Savings Growth and Liquidity Constraints." Quarterly Journal of Economics, 109 (1994), 83-109.

Lucas, R. E. "On the Mechanics of Economic Development." Journal of Monetary Economics 22 (1988), 3-42.

Mommsen, W. J. and W. Mock (eds.). The Emergence of the Welfare State in Britain and Germany: 1850-1950. Croom Helm: London, 1981.

Maddison, Angus. Phases of Capitalist Development. Oxford University Press: Oxford, 1982. 
Raffelhueschen, B. "Funding Social Security through Pareto-optimal Conversion Policies", Journal of Economics 7, Supplement (1993), 105-131.

Rogerson, Richard. "Indivisible Labor, Lotteries, and Equilibrium.” Journal of Monetary Economics 21 (1988), 3-16.

Romer, P. M. "Increasing Returns and Long-run Growth." Journal of Political Economy 94 (1986), 1002-37. 